\title{
Akdeniz Adalarına Sürgün Edilen Kırım Hanları
}

\author{
Crimean Khans Exiled to the Mediterranean Islands
}

\section{Özge TOGRAL ${ }^{*}$}

Öz: Kırım hanlarının Akdeniz adalarına sürgün edilmesi konusu, Kırım Hanlığı'nın Osmanlı Devleti’nin himayesi altına alınması tâbilik-metbûluk ilişkisi bağlamında ele alınmıştır. Osmanlı Devleti, Kırım Hanlığı tahtına geçecek hanın belirlenmesi gibi durumlarda müdahale etmiştir. Bilhassa Osmanlı siyasetine uyum sağlamayan hanların tayin ve azillerinde Osmanlı Devleti'nin kararı etkili olduğu gibi azledilen hanların nerede ikamet edeceği konusunda da yine padişah kararı etkili olmuştur. Azledilen Hanlar, Kırım'da iç karışıklıklara neden olma ihtimalinden dolayı sürgün edilmişlerdir. Azledilen hanlar dışında kalgay ve nureddîn makamında bulunan hanlık mensuplarının da sürgün edilmesi söz konusudur. Özellikle Rodos başta olmak üzere çeşitli Akdeniz adalarına sürgün edilmiştir. Sürgün sebebi ise Hanlık idare merkezine uzak olması ve dış dünya ile olan ilişkileri kontrol altında tutmanın ada yaşantısıyla daha kolay olabileceği fikri etkilidir. Söz konusu yapılan çalışma dahilinde, Akdeniz adalarına sürgün edilen Kırım Hanları hakkında bilgi vererek, sürgün nedenleri ve sürgün sırasındaki uygulamalar Osmanlı Arşiv belgeleri ışı̆̆ında ve çeşitli araştırma ve inceleme eserleri incelenerek değerlendirilecektir.

Anahtar sözcükler: Akdeniz, Kırım Hanlığg, Sürgün, Osmanlı Devleti

Abstract: The the exile Crimean khans to the Mediterranean islands, under the auspices of the Ottoman Empire, shows the Crimean Khanate was dealt with in the context of the relationship of loyalty domination. For this reason the intervention of the Ottoman State in the Crimean Khanate, in particular, the decision of the sultan was influential in the appointment and dismissal of those khans who did not fit in with Ottoman politics. At the same time, the Ottoman State decided where these dismissed khans would live. The deported Khans were exiled because they were thought to have caused internal disturbances in the Crimea. Apart from the Crimean khans who were dismissed, theose members of the Crimean family called kalgay and nureddin were also exiled. They were exiled to various Mediterranean islands, principally to the island of Rhodes. The reason for their exile to the Mediterranean islands was to be remove thie influence from the center of the khanate administration and exercise control over the exiles' connection with the outside world. These were the reason why exile to the Mediterranean islands was chosen. Within the scope of this study, information concerning the exiled Crimean Khans is given and reasons for their exile are examined. In addition, documents from the Ottoman archive from the time of their exile are evaluated through examining various works of research and investigation.

Keywords: Mediterranean, Crimean Khanate, Exile, Ottoman State

\section{Giriş}

Kırım Hanlığı’nın Osmanlı himayesi altına alınması ve hanların Akdeniz adalarına sürgün edilmesi konusunda, Kırım Hanlığı’nda ortaya çıkan siyasi karışıklıklara ve Osmanlı Devleti'nin

\footnotetext{
* Doktora Öğrencisi, Akdeniz Üniversitesi, Sosyal Bilimler Enstitüsü, Tarih Anabilim Dalı, Antalya. ozgetogral@gmail.com
} 
izlediği Karadeniz politikasına değinmek yerinde olacaktır.

Kırım, coğrafi konumu nedeniyle Osmanlı Devleti’nin Kuzey bölgesindeki güvenliği için öneme sahiptir. Özellikle; Kefe, Suğdak, Mengup, Kerç ve Kafkas sahilinde yer alan Koba, Taman ve Azak şehirlerinin güvenliğini sağlamak Osmanlı Devleti'nin en önemli amaçlarından biridir (Kurat 1977, 217). Güvenlik dahilinde esas amaç, bölgedeki ticaretin sekteye uğramasını önlemektir (Kamalov-Mirgaliyev 196). Kırım Hanlık idaresinde, Han ailesinin ve kabile beylerinin söz sahibi olması, Kırım Hanlığı'nda karışıklıklara neden olmuştur. Özellikle Şırın Beyi Eminek Mirza, Cenevizlilere karşı Osmanlı Devleti'nin desteğini alma yoluna başvurmuştur. Nitekim Fatih Sultan Mehmet'in takip ettiği Karadeniz politikası nedeniyle 1475 y1lında Gedik Ahmet Paşa güçlü bir donanma ile Kefe ve Kırım sahillerinde bulunan Cenevizlilere ait tüm limanlar ele geçirilmiştir. Kırım Hanlığı iç işlerindeki karışıklıktan yararlanan Cenevizlilerin, hapse attı̆̆ 1 Mengli Giray, Kefe'nin fethi sırasında Gedik Ahmet Paşa tarafindan hapisten çıkarılmıştır. Mengli Giray, Cenevizlilere yakınlığı olan Nur Devlet'i hanlık tahtından uzaklaştırarak tahta kendisi geçmiş ve Gedik Ahmet Paşa ile anlaşma yaparak Osmanlı tâbiliğini kabul etmiştir (İnalcık 2002, 451).

1476 ve 1478 'de Eminek Mirza'nın Fatih Sultan Mehmet'e gönderdiği bitikler Osmanlı tabiliği siyasi boyutta önem kazanmıştır. Nitekim; 1478 tarihli bitikte, Eminek Mirza, iç karışıklıklar nedeniyle Nur Devlet’ten kimsenin memnun olmadığını ve Mengli Giray'ın Osmanlı tabiliğinde tekrar Kırım tahtına çıkmasını istemiştir (Özyetgin 1996, 8-9). Bu nedenle, hem Kırım Hanlığı'nın, Osmanlı himayesinde olması hem de Kırım tahtında güvenilir bir han olması gerekmiştir (Kurat 1972, 17; Vasary 2014, 333). Kırım'da yaşanan iç karışıklıklar ve taht kavgaları Osmanlı Devleti'nin Kırım Hanlığı üzerinde etkisine zemin hazırlamış ve Kırım tahtına geçecek hanın belirlenmesinde Osmanlı Devleti'nin desteği ön planı çıkmıştır. Bundan sonraki dönemlerde Osmanlı nüfuzu giderek artmıştır.

Nitekim, 1514 yılında Mengli Giray'ın vefatının ardından Osmanlı himayesini istemeyen kabile beyleri gibi Kırım önde gelenleri, Mehmed Giray'1, hanlık tahtına geçmesini sağlamışlardır. 1530'lu yıllarda Kırım'da iç karışıklıklar devam etmektedir. Mehmed Giray'ın vefatından sonra Saadet Giray ve I. İslâm Giray'ın taht mücadelesi nedeniyle Saadet Giray hanlığı bırakıp İstanbul'a gelince Kırım Hanlığı tahtına I. İslâm Giray geçmiştir. Fakat Osmanlı Devleti tarafından İslâm Giray'ın hanlığı tanınmamıştır. 1532'de Saadet Giray, İstanbul'da hanlı̆̆ kardeşi Sahib Giray'a teslim etmiştir. Sahib Giray, padişah menşuru alarak Osmanlı Devleti'nin tahsis ettiği askeri görevlilerle birlikte Kırım'a gitmiştir. Bunun yanı sıra Osmanlı Devleti, İslam Giray’a kalgaylık menşuru göndermiştir. Böylece; Kırım Hanlı̆̆ı yönetiminde Osmanlı Devleti'nin etkisi artmaya devam etmiştir. Her ne kadar Kırım ileri gelenleri Osmanlı himayesine karşı çıkmış olsa da 1534 yılından sonra Kırım Hanlığı'nın, Osmanlı metbûluğu kesinleşmiştir (İnalc1k 1996, 76).

Osmanlı Devleti'nin, Kırım Hanlığı'na müdahalesi hanlık tahtına geçecek hanın belirlenmesi gibi durumlarla sınırlı kalmamıştır. Özellikle Osmanlı siyasetine uygun hareket etmeyen ve uyum sağlamayan hanların azledilmeleri konusunda da Osmanlı Devleti etkili olmuştur. Nitekim azledilen hanların veya Kırım hanlığında iç karışıklıklara neden olacağı düşünülen Kalgay ("Kırım Hanlığı'nda veliahta verilen unvandır") ve Nureddîn ("ikinci veliaht makamı") makamında (Ayrıntılı bilgi için bk. Fisher 2009, 34-35; İnalcık 2017, 37-38). bulunan hanzadelerin rehin olarak nerede ikamet edeceğine padişah kararı etkili olmuştur. Hanlık idare merkezine uzak olması ve dış dünya ile olan ilişkileri kontrol altında tutmanın ada yaşantısıyla daha kolay olabileceği için Doğu Akdeniz adalarına sürgün edilmiştir.

Bilindiği üzere sürgün kavramının iki farklı anlamı vardır. Birinci anlamı "iskan ve 
yerleştirme", ikinci anlamı ise bir "ceza" türüdür (Köksal 2006, 283-284). Ancak Kırım Hanlığı'nın özel statüsü dikkate alındığında Kırım hanlarının sürgün edilmesi siyasi boyuttadır (Ayrıntılı bilgi için bk. Daşçığlu 2007) Bu bağlamda Akdeniz adalarına sürgün edilen Kırım hanları ve hanzadeleri hakkında ayrıntılı bilgi vermek yerinde olacaktır.

\section{Canbek Giray Han}

Canbek Giray, Devlet Giray Han'ın torunu ve Şakayık Mübarek Giray'ın oğludur (Giray 1287, 42). 1610 yılında Kırım Hanı olan Canbek Giray, 1624 yılında Osmanlı Devleti'nin yardımı ile Mehmed Giray ve Şahin Giray’ı hanlıktan uzaklaştırmıştır. Ancak II. Osman döneminde İran seferi sırasında Serav'da mağlup olduktan sonra Canbek Giray Rodos'ta ikamete memur edilmiştir (Kırımî 1927, 118). Kalgay Şahin Giray'ın isyanı nedeniyle III. Mehmet Giray azledilince, Canbek Giray Rodos'tan gelerek tekrar han tayin edilmiş̧ir (Uzunçarşı1l1 1982,10-11).

Canbek Giray, Mehmet Giray'a yardım etmiş olan Ruslardan intikam almak için çalışmış ve Kantemir Mirza ile müştereken hareket etmiştir. Bu sefere hazırlanırken, Veziri azam Hüsrev Paşa'nın doğu seferine katılması emredilmiştir. Askerini göndermiş, ancak kendisi katılmamış bu sebeple hanlıktan azledilip yerine İnayet Giray Han olmuştur. Tekrar Rodos Adası'na ikamete memur edilmiş ve orada 1627 yılında vefat etmiştir. Rodos'ta, Murat Reis Camii'yi kuşatan kabristan içinde türbesi bulunmaktadır (Ülküsal 1980, 60; Balducci 1987,144; Çelikkol 1992, 48-49).

\section{Mehmed Giray Han}

Mehmed Giray Han, Selamet Giray'ın oğludur. Canbek Giray döneminde kalgay ve nureddîn makamına getirilmiştir. Yanbolu'da ikamet etmiştir (Giray 1287, 54). Yanbolu'da bulunurken büyük biraderi Bahadır Giray'ın yerine Kırım hanı olmuştur.

1644'de İslâm Giray'ın Kethüdası Sefer Gazi Ağa, İstanbul'a gelmiş ve veziriazam'ın isteği üzere Kırım Hanlığı'nın, İslâm Giray'a verileceği söylentisini çıkarmıştır. Bu nedenle Mehmed Giray'ın durumu sarsılmıştır. Ayrıca, Kırım halkının desteği olmadığı için aynı yıl içinde azledilmiş ve Rodos Adası'na ikamete memur edilmiştir (Kırımî 1927, 123; Uzunçarşılı 1982, 16).

\section{III. İslâm Giray Han}

Selâmet Giray'ın en büyük oğludur. Canbek Giray Han döneminde, Lehistan'a yapılan seferde esir düşerek yedi yıl orada kalmıştır. IV. Murad döneminde, Osmanlı tersanesinde bulunan on boyarın iadesi şartıyla serbest bırakılmıştır. Bir süre Yanbolu'da ikamet etmiştir. 1635 yılında Bahadır Giray'ın Kırım hanı olması üzerine kalgay tayin edilmiştir.

1641 yılında Bahadır Giray vefat edince han olmak için girişimde bulunmuştur. Bu nedenle IV. Mehmed Giray'ın isteği üzerine Rodos Adası'na sürgün edilmiştir. Ancak Sultan İbrahim üzerinde büyük nüfuzu olan Cinci Hoca desteği ile iki ay sonra İstanbul'a çağrılmıştır. 1644 yılında Mehmed Giray'ın yerine Kırım hanı olmuştur. 1654 yılında İslâm Giray, oğulları için düzenlettiği sünnet dügününde şirpençe hastalığı nedeniyle vefat etmiştir. Bunun üzerine Rodos'ta bulunan kardeşi Mehmed Giray, ikinci kez Kırım hanı olmuştur (Cevdet Paşa 1890, 39-41; Uzunçarş11 1982, 16-17; İnalcık 2001, 46).

\section{Şahin Giray}

Şahin Giray, Selâmet Giray Han'ın oğlu ve Mehmed Giray Han'ın kardeşidir. 1608 yılında Selâmet Giray, Kırım hanı olunca Şahin Giray'a, nureddîn'lik payesi verilmiştir (Öztürk 2002, 494). 1623 yılında Mehmet Giray, Sultan I. Ahmet tarafından Kırım hanı tayin edilince kardeşi Şahin Giray’a kalgaylık payesi verilmiştir (Naima 1968, 811; Ülküsal 1980, 60). 
Bir kahinin bir gün, kuş adını taşıyan devlet adamının dünyaya hakim olacağını söylemesi ve türlü entrikalar sonucu 1624'de Polonya'ya sığınmıştır. Daha sonra Rodos'ta ikamete memur edilen Şahin Giray, orada yedi yıl rahat bir hayat yaşadıktan sonra, başka bir kahinin, "kuş $a d l$ taşıyan bir kimsenin devletin başına belalar getireceğini" (Naima 1968, 1261) söylemesi üzerine, 1640 yılında Mustafa Paşa'ya Şahin Giray'ın başının kesilmesi emredilmiştir (Çelikol 1992, 46-47).

\section{Fethi Giray Han}

Kırım hanlarından, Devlet Giray Hanın oğludur. 1596 yılında Eğri Seferi'ne katılması istenmiştir. Kalgay Fethi Giray bir miktar Kırım askeriyle sefere katılmıştır. Eğri Seferi'nde fayda sağladığı için Sadrazam Sinan Paşa'nın teşvikiyle Kırım hanı tayin edilmiştir. Fakat Kırım tahtında Gazi Giray bulunduğu için halk iki handan hangisini tercih ederse berat ona verilecekti. Ancak İbrahim Paşa'nın iltiması nedeniyle Gazi Giray Han, Kırım tahtında kalmıştır. Bunun üzerine I. Fethi Giray İstanbul'a gitmiş ve ardından Rodos'ta ikamete memur edilmiştir. Sadece üç ay kadar kısa bir süre han olmuştur (Ülküsal 1980, 57-58).

Kabri, Murad Reis dergâhında Kırım Hanlarına mahsus türbede ve Şahin Giray'ın kabri yanında bulunmaktadır (Çelikkol 1992, 47).

\section{Devlet Giray Han}

II. Devlet Giray; Hacı Selim Giray'ın büyük oğludur (Giray 1287, 79). III. Gazi Giray Han, döneminde başlayan isyanlar devam ederken I. Kaplan Giray, Çerkezler ve diğer Kafkas toplulukları ile mücadeleye girişmiştir. Ardından Kabartay hududunda meydana gelen yenilgiden sorumlu tutulmuş ve hanlıktan azledilmiştir. Bu nedenle Rodos Adası'nda bulunan II. Devlet Giray, 1708 yılında ikinci kez Kırım hanı olmuştur (Kırımî 1927, 136; Öztürk 2002, $500)$.

Hacı Selim Giray dördüncü kez Kırım hanı olunca II. Devlet Giray, önce Çerkezler bölgesine kaçmıştır. Sonra Balıklava'ya ve oradan İstanbul'a gitmiştir. Ardından tekrar Rodos Adası'nda ikamete memur edilmiştir (Ülküsal 1980, 76-77).

\section{Âdil Giray Han}

Âdil Giray; Fetih Giray ile Kontes Potoçki'nin torunu ve Devlet Giray’ın oğludur. Bir süre Vize'de ikamet ettikten sonra Kırım hanlarının ricası üzerine Rodos'ta ikamet etmesi uygun görülmüştür (Uzunçarşıll 1982, 19).

Babası Devlet Giray'ın Leh boyarlarından birinin kızından dünyaya geldiği ve nesebi hakkında farklı dedikodular olan Âdil Giray, bir süre Boğdan'da çobanlık yapmıştır. Daha sonra Akmescit'e gelmiş ve nureddîn olarak tayin edilmiştir. Böylelikle Giraylar sülalesinden Çoban Giraylar ortaya çıkmıştır. Âdil Giray; 1665 'te Kırım hanı tayin edilmiş ve 1670 yılına kadar tahtta kalmıştır (Kırımî 1927, 125-126). Fakat asıl Giraylar, Çoban Girayları kendi soylarından görmedikleri için onların önemli görevlere gelmelerini engellemişlerdir (İnalcık 1996, 78).

\section{Selim Giray Han}

Selim Giray; Rezmi Bahadır Giray'ın oğludur. 1671-1704 yılları arasında dört kez Kırım tahtına geçmiş ve toplam yirmi üç yıl hanlık yapmıştır. Âdil Giray tarafından öldürülmek istenmiştir. $\mathrm{Bu}$ nedenle Şırın Kabilesi'ne sığınmıştır. Kırım'dan ayrılıp Yanbolu kasabasının Çulmak karyesinde ikamet etmeye başlamıştır. Osmanlı Devleti ile gelişen ilişkiler sonucu Âdil Giray’a karşı tepkiler nedeniyle azledilmiş̧ir. 1671 yılında Selim Giray Kırım hanı olmuştur. (Giray 1287, 63; Kırımî 1927, 139; Ülküsal 1980, 69; Eravc1 2009, 428). 
Çehrin Kalesi'nin muhasarasına katılmıştır. Buradaki başarısızlıktan sorumlu tutulunca 1677 y1lında hanlıktan azledilmiş ve bir süre Kefe'de kaldıktan sonra İstanbul'a gitmiştir. Murad Giray'ın isteği üzerine Rodos Adası'nda ikamete memur edilmiştir. 11. Hacı Giray'ın azledilmesinden sonra 1684 yılında tekrar Kırım Hanlığı'na getirilmiştir (Eravcı 2009, 428).

Mangup Kalesine giden Hacı Giray, Rodos Adası'na götürülmüş ve burada sürgün bulunan yeni han Selim Giray İstanbul'a gelmiştir (İnalckk 2015, 204). Oğlu Devlet Giray'ın hanlıktan azledilmesi üzerine dördüncü kez Kırım hanı tayin edilmiştir. (Mustafa Nuri Paşa 1992, 22).

\section{Murad Giray Han}

Kırım Hanı I. Selâmet Giray'ın torunu ve Mübarek Giray'ın oğludur. Mehmed Giray Han döneminde nureddîn rütbesi verilmiştir (Giray 1287, 72).

Selim Giray, azledilince bir çektiri ile acele Rodos'tan getirtilip Kırım Hanlığ 1 hattını bizzat padişahın elinden almış 1677 Kırım'a gönderilmiştir. Murad Giray, Rus ve Lehlilerle muharebeler yapmış ve II. Viyana Muhasarası'nda, Vezîriâzam ve Serdâr Kara Mustafa Paşa ile aralarının açılması ve muhasaranın başarısız sonuçlanmasından sorumlu tutulduğu için 1683 yılında azledilmiştir. Yanbolu'daki çiftliğine gönderilmiştir (Uzunçarş1lı 1982, 20-21).

\section{Hacı Giray Han}

I. Selâmet Giray' in torunu ve Kırım Giray'ın oğludur. Babasının vefatından sonra I. Selim Giray Han maiyetinde Nemçe seferlerine katılmıştır (Giray 1287, 73).

I. Viyana Seferi'nin başarısızlığından sorumlu tutulan Murad Giray, hanlıktan azledilince yerine II. Hacı Giray, 1683 yılında Kırım hanı olmuştur. Mirzalar ve Şırın beylerinin hoşnutsuzluğu ve iç karışıklıklar nedeniyle dokuz ay Kırım hanı olan II. Hacı Giray, 1684'de azledilmiştir. Ardından Rodos Adası'na sürgün edilmiş ve 1689 'da Rodos Adası'nda vefat etmiştir (Giray 1287, 74-75; Ülküsal 1980, 71-71; İnalcık 1996, 475-476).

\section{Devlet Giray Han}

II. Devlet Giray; Selim Giray Han'ın oğludur. Hem Hacı Giray Han hem de Saadet Giray Han dönemlerinde hanlıkta iki kez kalgaylık rütbesi verilmiştir (Giray 1287, 79).

Hacı Giray, kendi isteği ile tahttan çekilmesi üzerine 1699 yılında II. Devlet Giray, han olarak atanmıştır. Bu dönemde Kırım Hanlığı'nda gerçekleşen iç karışıklıklarla mücadele etmiştir. Fakat Kırım Hanlığı'nda yaşanan iç karışıklıklar artmaya devam edince 1702'de II. Devlet Giray azledilerek babası Hacı Selim Giray tekrar han olarak atanmıştır. Bunun sonucunda Rodos'ta ikamet etmeye memur edilmiştir. 13 Aralık 1708'de Rodos'ta sürgün iken I. Kaplan Giray'ın azledildikten sonra II. Devlet Giray tekrar Kırım hanı olarak atanmıştır (Giray 1287, 76-77; Kırımî 1927, 140; Öztürk 2002, 500).

\section{Safa Giray Han}

Selâmet Giray hanzadelerden, Nureddîn Safa Giray'ın oğludur (Giray 1287,77). Babas1 Nureddîn Safa Giray öldüğü zamanı henüz doğmamış olduğundan dünyaya gelince babasının adı konmuştur. Selim Giray'ı destekleyen ve onun tekrar han olmasını isteyen Kırım halkına rağmen Veziriazam Kadı Ali Paşa, Safa Giray'dan rüşvet alarak Kırım Hanlığı'na tayin edilmesini sağlamıştır. Safa Giray; han olmak için verdiği rüşveti ve çeşitli giderleri karşılamak için Yanbolu'dan Kırım'a gidince, Kırım'daki zenginlerden para vermeyenleri bahanelerle katletmeye başladığı için sefer zamanı yanına kuvvet gelmemiş ve gelenler ise Eflak hududunda sefere gitmeyerek isyan etmişlerdir. Bu isyan sonucunda azledilerek Hacı Selim Giray, üçüncü kez Kırım hanı olarak tayin edilmiştir (Uzunçarşılı 1982, 24). 
Safa Giray, "1104 Safer'inde hükümetten azl ile Rodos ceziresine nefy ve icla olunmuştur" (Giray, 1287, 78). Fakat Devlet Giray Kırım hanı iken, Safa Giray, affedilerek Karinabad kasabasında ikâmet etmeye başlamış ve 1703 yılında burada vefat etmiştir (Uzunçarşı1ı 1982, 25).

\section{Gazi Giray Han}

I. Selim Giray Han'ın oğludur. II. Devlet Giray zamanında nûreddin olmuş ve Çerkez nizamına tayin edilmiştir (Giray 1287, 72; İnalcık 1996, 453).

Osmanlı Devleti ve Rusya arasındaki barış siyasetini bozup Lehistan üzerine akın yaptığ için türlü entrikalar nedeniyle azledilmiştir (Kırımî 1927, 138; İnalcık 1996, 453; Öztürk 2002, 500). Bu kez Rodos yerine Rumeli'de Karinabad Karyesi'nde ikamet etmesine izin verilmiştir (İnalcık 1996, 453).

\section{Kaplan Giray Han}

El-hac Selim Giray Han'ın oğludur. Kaplan Giray, babasının hanlığından sonra Rodos Adası'nda ikameti sırasında 1680 yılında dünyaya gelmiştir (İnalcık 1996, 453; Öztürk 2002, 500). III. Gazi Giray 1707'de hanlıktan azledilince yerine I. Kaplan Giray, Kırım hanı olmuştur. Fakat Çerkezler, Kabartaylar, Kafkaslardan oluşan bir ittifakla karşı karşıya kalmıştır. Kabartay sinırında meydana gelen hezimetten sorumlu tutulduğu için 1708 'de azledilmiş ve Rodos Adası'na sürgün edilmiştir (Giray 1287, 84).

1713 yılında Devlet Giray azledilince I. Kaplan Giray, Rodos'tan çağırılarak ikinci kez Kırım hanı tayin edilmiştir (Giray 1287, 85; Ülküsal 1980, 82; İnalcık 2017, 351). I. Kaplan Giray; 1716 yılında Avusturya Seferi'ne katılma emri almıştır. Kırım kuvvetlerinin sefere geç katılmasından dolayı bu seferin sonucunu belirleyen Varadin Muharebesi'ndeki yenilgiden sorumlu tutulmuş ve hanlıktan azledilmiştir. Fakat 1730 'da II. Mengli Giray yerine üçüncü kez Kırım Hanı tayin edilmiştir (Kırımî 1927, 170; Ülküsal 1980, 86; Öztürk 2002, 501). 1736'da azlolunarak Sakız Adası'nda ikamete memur edilmiş ve 1738'de burada vefat etmiştir. Vasiyeti üzerine cenazesi Çeşme’ye defnedilmiştir (Çelikkol 1992, 49; İnalcık 2017, 354).

\section{Fethi Giray Han}

Selim Girayhanzâde II. Devlet Giray hanın oğludur. Kaplan Girayın üçüncü hanlığında nureddîn tayin edilmiştir (Giray 1287, 98). 1731 yılında Rodos'ta ikamete memur edilmiştir (BOA.C.HR. 68/3378).

Kaplan Giray hanlıktan azledilince II. Fethi Giray, Kırım hanı olmuştur. Avusturya'nın Eflak ve Boğdan'1 zapt etmesinin ardından Rusya'nın, Kırım'a saldırması nedeniyle bu felaketlerden II. Fethi Giray sorumlu tutulmuştur. Bu nedenle 1737 yılında hanlıktan azl edilmiştir (Ülküsal 1980, 90).

\section{Selâmet Giray Han}

II. Mengli Giray Han döneminde nureddîn ve daha sonra kalgaylık rütbesi verilmiştir (Giray 1287, 99). II. Mengli Giray, vefatından sonra Kırım hanı tayin edilmiştir. 1743 yılında hanlıktan azledilince Gelibolu'da ikamet ettirilmiştir. Bir süre sonra Yanbolu civarında ikamet etmeye başlamıştır (Ülküsal 1980, 93).

Fakat aynı yıl Selim Giray, Kırım hanı tayin edilince Selâmet Giray'ın, Kırım'dan tayin edilen mübaşir eşliğinde Gelibolu'ya gelmesi ve oradan çektirme sefinesi ile Rodos Adası'na gitmesi hakkında hüküm verilmiştir (BOA.C.MTZ. 1 /40). Bunun üzerine II. Selâmet Giray ve onun baş ağalık hizmetinde bulunan el-Hac Er Mirza ile birlikte Rodos'a sürgün edilmiştir. 
Burada cezirebend olarak ikamet etmeye memur edilmiş ve Rodos Adası'ndan başka bir yere gitmemesi hakkında Çavuşbaşı Ağa'ya hüküm verilmiştir (BOA.C.MTZ. 1/ 39)

\section{Arslan Giray Han}

Arslan Giray, II.Devlet Giray'ın oğludur. Kaplan Giray'ın hanlığı döneminde nureddîn, ağabeyi II. Fethi Giray döneminde ise kalgay olmuştur (Kırımî 1927, 179). II. Fethi Giray, azledilince kalgaylık görevi sona ermiş ve Vize Kasabası'nda oturmaya başlamıştır (Giray 1287, 103). Padişahların sarayında uzun süre harem ağalarına hocalık ettiği için saraya girme imkanı bulmuştur (Ülküsal 1980, 93). II. Selim Giray'ın 1748 yılında vefat etmesi üzerine Arslan Giray, hanlık tahtına geçmiştir (Öztürk 2002, 502).

Kırımlı Rıza Efendi'nin teşvikiyle 1756'da azledilen Arslan Giray, Sakız Adası'na sürülmüş, daha sonra Gelibolu'da oturmasına izin verilmiştir. 1756 yılında ikinci kez Kırım hanı tayin edilmiştir. Fakat tahta geçtikten üç ay sonra vefat etmiştir (Ülküsal 1980, 93).

\section{Azamet Giray}

Azamet Giray, III. Gazi Giray Han'ın oğludur. Sakız Adası'nda ikamete memur edilmiştir. Fakat kış aylarının yaklaşması nedeniyle bahardan önce Sakız Adası'na gidilemeyeceği için Dimetoka'daki çiftliğe gönderilmiştir. Bahar'ın başlangıcıyla birlikle mübaşir eşliğinde Sakız Adası'na gönderilmesi hususunda ilam gönderilmiştir (BOA.C.MTZ.1/3).

\section{Kırım Giray Han}

Kırım Giray; II. Devlet Giray'ın oğlu ve Arslan Giray'ın kardeşidir (Giray 1287, 106). Ekim 1758 'de Halim Giray'ın azledilmesi sonucunda yerine Kırım Giray (ilk hanlığı) atanmıştır. Halim Giray'ın azledilmesine yol açan Nogay isyanının alevlenmesinde Kırım Giray'ın da rolü olmuştur. İstanbul aslında Arslan Giray'ın atanmasına karar vermiş, ancak kabile güçlerinin kararlı muhalefeti karşısında Kırım Giray atanmıştır. Bu suretle İstanbul'un onayını almadan Kırım tahtına geçmiş bulunan yeni han (Öztürk 2002, 502) kendisini hiçbir zaman emniyette hissetmemiş, Baserabya'daki karargâhından ayrılmamıştır.

Kırım Giray, 1760 yılında Kozak istilasına karşı mücadele etmiştir. Arslan Giray'ın muhalefeti onu zayıflatan en önemli unsurlardan biridir. Bu nedenle Kırım Hanı'nın, Prusya Kralı Frederick ile iyi ilişkiler içinde bulunması İstanbul nezdinde hoş karşılanmamıştır. İstanbul onu bazı müzakerelerde bulunmak üzere merkeze çağırdığında azledilme endişesi ile gitmemiştir. Merkezin 1srarı üzerine, maiyetinin uyarılarına rağmen 1764'te İstanbul'a vard1ğında azledilerek, yerine III. Selim Giray, han tayin edilmiştir (Öztürk 2002,502). Azledilen Kırım Giray; Sakız Adası'na ikamete memur edilmiş ve 1765 yılında çektirme sefinesi ile Sakı'’a nakli için müstevin sefinelerden Kandola adlı Fransız Kaptan Sefinesi'nin tercümanı vasıtasıyla 500 kuruş verilen gemi ile adaya varması gerektiği hükmü verilmiştir (BOA.C.ZB. 3/113).

Ancak Kırım Giray, Sakız Adası'nda ikameti sırasında İstanbul'a adam gönderip asılsız söylentiler çıkartmıştır. Bunun için Selim Giray Han, Kırım Giray'ın, Sakız'dan, Rodos'a naklini istemiştir (BOA.C.HR. 10/463). 1768'de Osmanlı Devleti, Rusya ile muharebeye karar verildiğinde Maksud Giray muharebe için yeterli görülmemiş ve azledilmiştir. Bunun üzerine Kırım Giray, tekrar han tayin edilmiştir. Fakat han tayin edildikten yedi ay sonra vefat etmiştir (Ülküsal 1980, 94; Öztürk 2002, 503).

\section{Şahin Giray Han}

Şahin Giray; II. Devlet Giray Han'ın torunu ve Ahmed Giray'ın oğludur. 1770'ten itibaren 
Ruslar'ın, Kırım iç işlerine müdahale etmeye yönelik başlattığı saldırılar nedeniyle Şahin Giray, Devlet Giray aleyhinde girişimlerde bulunmuştur. 1771'de Kırım topraklarına girerek, Kırım hanlığını bağımsız bir hanlık yapmak için çabalayan Rus General Dolgorukij'in hazırladığı beyannameyi görüşmek amaciyla kurulan heyetle Petersburg'a gitmiş ve müzakerelere katılmıştır (Mustafa Nuri Paşa 1992, 65; Emecen 2010, 275). Kırım'da yaşanan taht kavgaları Rusya lehine bir durumdur. Nitekim 1774 Küçük Kaynarca Antlaşmasının imzalanmasından sora Rusya, Kırım üzerindeki emelleri için Şahin Giray’ı desteklemiştir.

Şahin Giray; 1777 yılında Rusya'nın desteğiyle Kırım hanı olmuştur. Aynı yıl içinde Ruslar Kırım'1 limanlarına saldırmış ve 1781'de artan Rus baskısı nedeniyle Kırım ahalisi, Şahin Giray'a karşı isyan etmiştir. Şahin Giray'ın hanlığı döneminde iç karışıklıklar ve taht mücadeleleri devam etmiştir (Fisher 2009, 99-100). 1783 yılında Kırım'1 ilhak etmiştir.1784 yılında Petersburg'a gitmiş ve I. Abdülhamit'ten af dileyerek Osmanlı topraklarına iltica etmiş ve daha sonra Rodos Adası'na sürgün edilmiştir. (Ülküsal 1980, 117-118; Mustafa Nuri Paşa 1992, 161163; Köse 2010, 354-355). Fakat I. Abdülhamit bu sürgün sırasında mübaşirlere, Şahin Giray'ın idam edilmesi emrini vermiş olmasına rağmen bu emir uygulanamamışır. Ancak " 1787 A ̆gustosu'nun ikinci haftası mahfuz tutulduğu yerde boğularak idam edilmişti” (Emecen 1984, 332-333). Kabri ise Rodos'ta Murat Reis Camii'nin kabristanında bulunmaktadır (Balducci 1987,143).

Son Kırım Hanı Şahin Giray döneminden sonra da hanlık mensuplarının sürgün edildiği görülmektedir. Özellikle, Kırım'in ilhak edilmesinden sonra tamamen Rus kontrolünde olan hanlık bölgesinde ikamet etmemeye başlamışlardır. 1792 yılından sonra İstanbul ve Edirne civarında yaşamaya devam eden hanlık şehzadeleri de sürgün edilmiştir. Haklarında bulunan belgelerin sınırlı olması nedeniyle ayrıntılı bilgi verilmekten kaçınılmıştır. Ancak, daha önce Kırım Hanlığı'nda Kalgay ve Nureddin makamında bulunan Şahbaz Giray ve Baht Giray'ın sürgün edilmesi sadece azledilen hanların değil aynı zamanda hanlık veliahtlarının da sürgüne gönderilmesi, sürgünlerin niteliğini açıklamak bakımından dikkate değerdir.

\section{Şahbaz Giray Han}

Sahib Giray döneminde Kırım'dan, İstanbul'a firar eden Şahbaz Giray, Osmanlı Devleti tarafından Kuban ve Taman'a gönderilmiştir. 1775 yılında Devlet Giray Kırım hanı olunca, Şahbaz Giray kalgay tayin edilmiştir (Ülküsal 1980, 99-102). 1787'de Osmanlı Devleti Kuban Nehri civarındaki Türk kabilelerinin başına han tayin edilen Şahbaz Giray, Kuban Hanı unvanı almıştır (İnalcık 2017, 36).

Nitekim birkaç kaynakta kendisinden "hilaf-ı kuban hanı şahmetlü Şahbaz Giray Han hazretleri" olarak bahsedilmektir. Daha sonraki y1llarda Hayrabolu'da ikamet etmeye başlayan Şahbaz Giray; burada bulunan on iki nefer eşkıyanın reisleri olan Hacı oğlu Mehmed ve Kalyoncu Mustafa adlı eşkıyaları himaye ettiği için Bozcaada'ya sürgün edilmiştir. Ancak bu sürgün emrine uymamış ve amcası Sahib Giray'ın müsaadesi olmadığı sürece Bozcaada'ya gitmeyeceğini beyan etmiştir. Bunun üzerine yedi nefer süvariyle Çatalca civarına firar etmiştir (BOA.C.HR. 81/4014)

\section{Baht Giray Han}

Baht Giray, Kırım Giray Han'ın oğludur. II. Kaplan Giray'ın hanlık döneminde nureddînlik makamına getirilmiştir (İnalcık 2017, 355). 19 Ağustos 1787 tarihinde Osmanlı Devleti'nin Rusya'ya savaş ilan ettiği dönemde Şahbaz Giray'a verilen Kuban Hanı ünvanı, Baht Giray’a da 1789 yılında verilmiş ve Boğdan'daki savaşlara katılmıştır (İnalcık 2017, 36). Hatta Osmanlı Rus savaşının sürdüğü 1791 yılında eski Kuban Hanı Şahbaz Giray’a düşmana karşı Baht Giray 
Han başkanlığında birlikte savaşmalarına dair hüküm verilmiştir (BOA.C.HR. 65/3243).

1792 Yaş Antlaşmasının imzalanmasından sonra, Baht Giray, İstanbul'a getirilmiştir. Bu tarihten sonra Kırım Hanlığı'nı yeniden kurma fikri tamamen sona ermiştir (İnalcık 2017, 36). Aynı yıl içerisinde Baht Giray Han, Midilli Adası'na sürgün edilmiştir ( BOA.C.HR. 63. 3144)

1804 yılında ise eski Kuban Hanı Baht Giray, Girit Adası'na sürgün edilmiş ve kendisini Girit'e götürmek için Kapıcıbaşı Yeğen İbrahim Ağa, mübaşir olarak tayin edilmiştir (Köksal 2006, 297). Şahin Giray döneminde 1783 yılında Rusya'nın Kırım'ı ilhak etmesi ve 1792 Yaş Antlaşmasından sonra Kırım hanlık mensuplarının İstanbul'a geldiği ve buradan Akdeniz adalarına sürgün edildiği tespit edilmiştir.

Nitekim; Baht Giray Han'ın kardeşi Mehmed Giray Rumeli'de fesat çıkardığı için 1792'de Rodos'a evladı ile birlikte sefine aracılığıyla gönderilmiştir (BOA.HAT.245/13819). Daha sonra İstanbul'a gelmiş ve Eyüp civarında, huzuru bozacak hareketlerde bulunarak fesat çıkarttığı için 1800 yılında tekrar Rodos'a sürgün edilmiştir (BOA.C.ZB. 11/512).

Yukarıda belirtildiği üzere; Kırım, tamamen Rus kontrolünde olduğu için 1792 yılından sonra İstanbul ve Edirne civarında yaşamaya devam eden hanlık şehzadeleri de sürgün edilmiştir. Haklarında bulunan belgelerin yetersiz olması nedeniyle ayrıntılı bilgi verilmekten kaçınılmıştır. Fakat bilinmektedir ki, Kırım hanları ve hanlık mensupları Rodos başta olmak üzere Limni, Midilli, Sakız, Bozcaada, Girit ve Kıbrıs Adalarına sürgün edildikleri tespit edilmiştir. Nitekim Kıbrıs'a sürgün edilen Âdil Giray'ın 5 Ocak 1791'de affedildiği bilinmektedir (BOA.C.HR. 65/3243).

Osmanlı Devleti tarafından affedilerek tekrar Kırım Hanı tayin edilenler vardır. Fakat Kırım Hanlık mensuplarının isteği üzerine sürgünden dönen ve İstanbul veya Edirne civarına yerleştirilenler de bulunmaktadır. Örneğin; İzzet Giray Sultanın affedilmesi için Bahadır Giray tarafından Bâb-1-Âlî'ye mektup gönderilmiştir. Nitekim "li-ecli't-tedib nefy ü iclâ ve nefy ü tağrîb Hayrabolu'da mukim İzzet Giray Sultan şimdiye kadar tehzib-i ahlak etmiş olduğu beyanıyla afv u ttlak hususuna" ifadelerinin bulunduğu bu mektupta; Eğer İzzet Giray, hiçbir meseleye karışmaz ve Hayrabolu'daki hanesinde kendi halinde oturursa affedilerek Midilli Adası'na sürgün edilmeyeceği hususundadır (BOA.C.ZB. 7/349).

Bunun dışında sürgün edilen Kırım hanlarının valideleri ve hemşirelerinin de sürgün yaşamının sona ermesinde etkili olabileceği düşünülebilir. Nitekim, Rodos ve Limni'ye sürgün edilen Hacı Giray, Saadet Giray, Devlet Giray sultanların valideleri Ayşe ve hemşiresi Saliha hanımlar tarafindan Bâb-1-Âlî’ye 1795 tarihinde gönderdikleri arzuhallerinde, adı geçen hanlık mensuplarının uzun süredir sürgün bulundukları ve ızdırab hallerinden dolayı affedilmelerini istemişlerdir (BOA.HAT. 202/10315).

Sürgün kararı verilmesinin pek çok sebebi vardır. Fakat başlıca nedenlerden biri yeni han tayin edilen hanın isteği üzerine eski han, kalgay ve nureddîn olarak adlandırılan Kırım Hanlığ şehzadelerinin, Kırım iç karışıklarına neden olma ihtimalinden ötürüdür. Nitekim Selim Giray Han'ın, Sakız Adası'nda sürgünde bulunan Kırım Giray'ın sürgün yerinin değiştirilerek Rodos Adası'na gönderilmesini istediği gibi (BOA.C.HR. 10/463) sürgünler Kırım hanlarının istekleri doğrultusunda yapılmıştır. Diğer bir neden ise; uygunsuz hareketlerinden dolayı sürgün edilmişlerdir. Uygunsuz hareketler olarak tabir edilenler arasında eşkıyayı himaye etmek vardır. Nitekim, daha önce bahsedildiği üzere Hayrabolu'da ikamet eden Şahbaz Giray'ın, burada himayesinde on iki nefer eşkıyanın bulunduğu Hacı oğlu Mehmed ve Kalyoncu Mustafa adlı eşkıyaları himaye ettiği için Bozcaada'ya sürgün edilmiştir (BOA.C.HR. 81/4014).

Ayrıca Edirne ve İstanbul civarında ikamet ettikleri sırada birbirleriyle mücadele ettikleri 
için sürgün edilen Kırım hanlık mensupları da vardır. Mengli Giray'ın, Eyüp Giray'ın haremine girerek tüfekle öldürerek çiftliğini zapt etmesi üzerine Rodos'a sürgün edilmiş ve burada kalebent edilmiştir (Daşçıŏlu 2007,161). İncelenen arşiv kayıtlarına göre, sürgün cezası alan Kırım hanları sürgün edildikleri bölgeye devlet görevlileri tarafından götürülüp yerleştirilmişlerdir. Nitekim Hacı Giray'ın, sürgünü sırasında kapıcıbaşı eşliğinde Rodos Adası'na gönderilmiştir. (BOA.C.HR. 14/669). Kırım hanlarının sürgün edildiği bölgeye götürülmesi için Kapıcıbaşı dışında Çavuş tayini de söz konusudur. Örneğin ; Selimgirayzâde Devlet Giray ve Bayezid Giray, Limni Adası'na Çavuş mübaşeretiyle gönderilmişlerdir. (BOA.C.ZB.10 /462). Kırım hanlarının ve hanlık mensuplarının, sürgün edildikleri bölgeye gönderilirken Hasekilerin de tayin edildiği görülmektir. Örneğin; Adil Giray ve Saadet Giray’1, Rodos’a götürmek için Hassa Hasekilerinden iki nefer haseki tayin edilmiştir. Görevlendirilen hasekilerin her birine yüzer guruş harcırah verilmiş ve toplamda iki yüz guruş harcırah verildiği baş muhasebe tarafından kaydedilmiştir (BOA.C.HR. 33/1601).

Kırım hanları ve hanlık mensupları sürgün edildikleri adalara çektiri tabir edilen gemiler ile gönderilmişlerdir. Sürgün sırasında yanlarında götürdükleri eşyalar hakkında genel bir değerlenme için veriler oldukça sınırlıdır. Fakat, Midilli'ye sürgün edilen Baht Giray'ın dairesi için gerekli olan eşyalar, Cebehane-i Amire'den ve Mehterhane-i Amire'den mihmandarı tarafindan satın alınarak adaya gönderilmiştir. Söz konusu bu eşyalar; bir adet telli yorgan, bir adet mühim yorgan gibi yorgan çeşitleri, bir adet müstemim yüz yastığı, baş yastığı gibi yastık çeşitleri, yatak yüzü beyaz futa, çift döşek şilte, yorgan maa çarşaf, (BOA.C.HR. 63/3144) çuka perde, yatak odası ve sair odalara yapağı, kamış, yorgan, masa, çarşaf, çuka yün ile şilte (BOA.C.MTZ. 5 /208) havlu makrama, bir adet kazgan, kahve ibriği, iki adet fulâd taâm tepsi vb. günlük yaşamda gerekli olanları içermektedir (BOA.C.HR. 63/3144).

Ayrıca azledilen hanlar veya yeni tayin edilen hanların akrabaları herhangi bir iç karışıklığa sebep olmamaları için Osmanlı Devleti'nin belirlediği yerlere özellikle, Karinabad, Yanbolu, Çatalca, Aydos, İslimye ve Tekirdağ gibi yerlerde bulunan çiftliklere yerleştirilmişlerdir. Buralarda geçimlerini sağlamak için has, zeamet, sâlyâne tahsis edildiği bilinmektedir. Nitekim eski Kırım Hanı Devlet Giray'ın oğlu Mehmed Giray, Sakız Adası'na sürgün edildiğinde sâlyânesi İzmir Gümrügü̈'nden karşılanmıştır. Fakat affedilerek Rumeli'de ikametine izin verildiğinde sâlyânesi İstanbul Gümrüğü'nden verilmeye başlanmıştır (BOA.C.MTZ. 3/119). Ancak, sürgün edilen han ve hanlık mensuplarının ekonomik olarak nasıl desteklendiği konusunda sınırlı belgeler olduğu için genel bir yargıda bulunmak olanaksızdır.

\section{Sonuç}

Yapılan çalışma kapsamında incelenen araştırma eserler ve Başbakanlık Osmanlı Arşiv belgelerine göre azledilen Kırım hanlarının, İstanbul'a geldiği ve birçoğunun buradan Rodos Adası başta olmak üzere Sakız ve Midilli, Kıbrıs, Bozcaada, gibi Akdeniz adalarına sürgün edildikleri tespit edilmiştir. Fakat sadece Kırım tahtından azledilen hanlar değil, nureddin ve kalgay makamında bulunan hanlık mensupları da Akdeniz adalarına sürgün edilmişlerdir.

1783 yılında Kırım'ın ilhakı ve 1792 yılından sonra İstanbul ve Edirne civarında yaşamaya devam eden hanlık şehzadelerinin de sürgün edildiği tespit edilmiştir. Sürgün edilme nedenleri arasında Kırım Hanlığı'nda olası iç karışıklıkları önlemektir. Bu genellikle yeni tayin edilen hanın isteği üzerine uygulanmıştır. Bunun dışında yerleştikleri bölgede eşkıyayı himaye etmek gibi uygunsuz hareketlerde bulundukları için Akdeniz adalarına sürgün edilmişlerdir. Fakat Kırım han ve şehzadelerinin sürgün süresi boyunca ekonomik olarak nasıl desteklendiği konusunda kısıtlı belgeler olduğu için kesin bir yargıda bulunmaktan kaçınılmıştır. 


\section{KAYNAKÇA}

Kırımî A. bin H. (1927). Umdet üt-Tevarih. İstanbul 1927.

Kurat A. N. (1972). IV. ve XVIII. Yüzyllarda Karadeniz'in Kuzeyinde Türk Kavimleri ve Devletleri. Ankara 1972.

Balducci H. (1987). Rodos'ta Türk Mimarisi. Çev. C. Rodoslu. Ankara 1987.

Cevdet Paşa. (1890). Kırım ve Kafkas Tarihçesi, 1890.

Çelikkol Z. (1992). Rodostaki Türk Eserleri ve Tarihçe. Ankara 1992.

Daşçıŏlu K. (2007). Osmanlı'da Sürgün. İstanbul 2007.

Eravcı H. M. (2009). "Selim Giray". İslâm Ansiklopedisi 36 (2009) 428-429.

Emecen M. F. (2010). "Şahin Giray”. İslâm Ansiklopedisi 38 (2010) 275-277.

Emecen M. F. (1984). "Son Kırım Hanı Şahin Giray’ın İdamı Meselesi ve Buna Dair Vesikalar”. İstanbul Üniversitesi Edebiyat Fakültesi Tarih Dergisi 34 (1984) 315-347.

Fısher A. (2009). Kırım Tatarları. Çev. E. B. Özbilen. İstanbul 2009.

Giray H. (1287). Gülbîn-i Hânân. İstanbul 1287.

İnalc1k H. (1996). "Giray”. İslâm Ansiklopedisi 14 (1996) 76-78.

İnalcık H. (2017). Kırım Hanlı̆̆ Tarihi Üzerine Araştırmalar 1441-1700. İstanbul 2017.

İnalcık H. (2001). “İslâm Giray III”. İslâm Ansiklopedisi 23 (2001) 46-47.

İnalcık H. (2015). Devlet-i ‘Aliyye Osmanlı İmparatorluğu Üzerine Araşttrmalar-III. İstanbul 2015.

İnalcık H. (1996). "Hacı Giray II". İslâm Ansiklopedisi 14 (1996) 475- 476.

İnalcık H. (1996). "Gazi Giray III”. İslâm Ansiklopedisi 13 (1996) 453.

İnalcık H. (2002). "Kırım”. İslâm Ansiklopedisi 25 (2002) 450-458.

Kamalov İ. \& Mirgaliyev İ. (2008). “Altın Orda-Osmanlı Münasebetleri”. Gazi Akademik Bakış Dergisi 2/3 (Kış 2008) 187-196

Köksal O. (2006). "Osmanlı Hukukunda Bir Ceza Olarak Sürgün ve İki Osmanlı Sultanının Sürgünle İlgili Hatt1-1 Hümayunları”. OTAM 19 (2006) 283-341.

Köse O. (2010). “Osmanlı Devleti Tarafından Kırım ile İlgili Rusya'ya Verilen Resmi Belge 'Sened' (1784)". History Studies International Journal of History 2/2 (2010) 353-362.

Mustafa Nuri Paşa (1992). Netâyicü'l-Vukuât Kurumu ve Örgütleriyle Osmanlı Tarihi III-IV. Ed. Neşet Çağatay. (2009) Ankara.

Naima Mustafa Efendi (1968). Naima Tarihi III. Çev. Z. Danışman. İstanbul 1968.

Öztürk Y. (2002). "Kırım Hanlığı”. Türkler 8 (2002) 480-513.

Özyetgin A. M. (1996). Altınordu, Kırım ve Kazan Sahasına Ait Yarlık ve Bitiklerin Dil ve Üslup İncelenmesi. Ankara 1996.

Uzunçarşı1ı İ. H. (1983). Osmanlı Tarihi, III/I. Ankara 1983.

Uzunçarşılı İ. H. (1982). Osmanlı Tarihi, III/II. Ankara 1982.

Ülküsal M. (1980) Kırım-Türk Tatarları (Dünü-Bugünü-Yarını). İstanbul 1980.

Vasary I. (2014). "Kırım Hanlığı ve Büyük Orda(XV-XVI Yüzyıl) Hâkimiyet Uğruna Mücadele”. Çev. Serkan Acar. Tarih Incelemeleri Dergisi XXIX/1 (2014) 327-340.

\section{Başbakanlık Osmanlı Arşivi}

BOA. C.HR. (Cevdet Hariciye Evrakı). Dosya no: 10, Gömlek no: 463.

BOA. C.HR. (Cevdet Hariciye Evrakı). Dosya no: 14, Gömlek no:669.

BOA. C.HR. (Cevdet Hariciye Evrakı). Dosya no: 63, Gömlek no: 3144.

BOA. C.HR. (Cevdet Hariciye Evrakı). Dosya no: 65, Gömlek no: 3243.

BOA. C.HR. (Cevdet Hariciye Evrakı). Dosya no: 68, Gömlek no: 3378.

BOA. C.HR. (Cevdet Hariciye Evrakı). Dosya no: 33, Gömlek no: 1601.

BOA. C.HR. (Cevdet Hariciye Evrakı). Dosya no:81, Gömlek no: 4014. 
BOA. C.MTZ. (Cevdet Eyalet-i Mümtaze Evrakı). Dosya no:1, Gömlek no: 39.

BOA. C.MTZ. (Cevdet Eyalet-i Mümtaze Evrakı). Dosya no:1, Gömlek no: 40.

BOA. C.MTZ. (Cevdet Eyalet-i Mümtaze Evrakı). Dosya no:1, Gömlek no:3.

BOA. C.MTZ. (Cevdet Eyalet-i Mümtaze Evrakı). Dosya no:5, Gömlek no: 208.

BOA. C.ZB. (Cevdet Zabtiye Evrakı). Dosya no: 3, Gömlek no: 113.

BOA. C.ZB. (Cevdet Zabtiye Evrakı). Dosya no: 7, Gömlek no: 349.

BOA. C.ZB. (Cevdet Zabtiye Evrakı). Dosya no:10, Gömlek no:462.

BOA. C.ZB. (Cevdet Zabtiye Evrakı). Dosya no: 11, Gömlek no: 512.

BOA. HAT. (Hatt-1 Hümayûn Tasnifi Evrakı) Dosya no:202, Gömlek no: 10315.

BOA. HAT. (Hatt-1 Hümayûn Tasnifi Evrakı) Dosya no: 245, Gömlek no: 13819. 